Revista de Negócios_ISSN 1980.4431_vol. 18, n.1, p.42_52, 2013_DOI:10.7867/1980-

431.2013v18n1p42_52

Edição Especial: Produção de Conhecimento Científico em Marketing

\title{
Diga-me o que publicas e te direi quem és: Perspectivas e resistências na publicação da produção de conhecimento em Marketing
}

Tell me what you publish and I will tell you who you are: Perspectives and resistances in the publish of Marketing knowledge production

\section{João Felipe Rammelt Sauerbronn}

Universidade do Grande Rio

PPGA - Programa de Pós-Graduação em Administração e-mail: joao.sauerbronn@gmail.com

Recebido em 18 de fevereiro de 2013. Aprovado em 14 de março de 2013

Editor Responsável: Edson Roberto Scharf, Dr.

Autor convidado para edição especial

\begin{abstract}
Resumo
O conhecimento gerado e publicado na área de marketing parece estar comprometido com a manutenção do status quo e tem se mostrado distante de ser relevante para a sociedade. No presente ensaio procuro mostrar minha preocupação relacionada a duas questões: a aparente acomodação da comunidade acadêmica brasileira em aceitar orientações de pesquisa que estão descoladas da realidade local; e a consolidação de uma perspectiva monoparadigmática positivista na pesquisa em marketing, que reprime a pluralidade epistêmica. A busca por interpretações a respeito das razões para que isso aconteça é o objetivo desse artigo. Dessa forma, conduzo o leitor por um trajeto que se inicia com a discussão a respeito das origens
\end{abstract}

e intenções das organizações que têm se preocupado em orientar a geração de conhecimento na área. Em seguida, apresento ao leitor algumas reflexões a respeito dos efeitos dessa orientação externa sobre a academia e a pesquisa acadêmica de marketing no Brasil, mais especificamente. Apresento os reflexos sobre a atividade docente, cada vez mais precarizada e focada no produtivismo, e sobre a formação de novos pesquisadores, que se tornam distantes da reflexão e da observação crítica dos problemas de marketing. Com isso, as possibilidades de expansão do conhecimento da área e do aumento de sua relevância tornam-se profundamente limitadas. Alguns pontos de tensão são expostos com o objetivo de gerar um possível desconforto, afinal já 
Diga-me o que publicas e te direi quem és: Perspectivas e resistências na publicação da produção de conhecimento em Marketing

é claramente perceptível o desencanto com a área manifestado por acadêmicos de fora dos EUA. Ao fim, o leitor é levado a considerar algumas possibilidades para recuperação da relevância do conhecimento gerado na área, baseadas i) na participação dos acadêmicos locais em um debate que envolva a orientação do que é produzido na área, ii) no reconhecimento da multiplicidade e da pluralidade da área, iii) no estímulo à produção de conhecimento substantivo, e iv) no cuidado com a formação de novos pesquisadores.

Palavras-chave: Marketing. Relevância da área de Marketing. Conhecimento em Marketing.

\section{Abstract}

The knowledge generated and published in marketing seems to be committed to maintaining the status quo and has been distant to what is relevant to society. In this essay I try to show my concern related to two issues: the apparent accommodation of the academic community to accept research orientations that are detached from local realities; and the consolidation of a positivist monoparadigmatic perspective in marketing research that represses the epistemic plurality. This paper's main purpose is to propose an appreciation about the reasons why it happens. Thus, the reader follows a journey that starts with a discussion about the origins and intentions of the organizations that have been involved in guiding the knowledge generation in the area. After that I present some reflections about the effects of external guidance over marketing research in Brazil. I offer reflections on the teaching activity, increasingly precarious and focused on productivism; and the training of new researchers, who become distant from reflexive thinking and critical observation of marketing problems. Some points of tension are exposed in order to generate a possible discomfort, after all there is some disenchantment with the area expressed by academics from outside the U.S. At the end, the reader is led to consider some possibilities for recovering the relevance of the knowledge generated in the area, based on i) the participation of local scholars in a debate involving the orientation of what is produced in the area, ii) the recognition of the multiplicity and the plurality of the area, iii) the production of substantive knowledge, and iv) the careful training of new researchers.

Keywords: Marketing; Relevance of Marketing research; Marketing knowledge

\section{Introdução}

Pensar/repensar a produção de conhecimento na área de marketing é sempre oportuno. Afinal, o sentimento de desconforto com o mundo à sua volta deve ser frequente na carreira do acadêmico. Nesse sentido, não poderia deixar de agradecer ao instigante convite da Editoria da Revista de Negócios para escrever esse ensaio, que trata de uma discussão que é muito interessante para a Academia: a geração e disseminação do conhecimento.

Como o título já sugere, a ideia é trazer algumas reflexões a respeito do conhecimento produzido e publicado na área de marketing. Desde a proposta feita pela Editoria até a construção desse artigo, em nenhum momento foi minha intenção desenvolver um levantamento de dados a respeito do que é publicado na Academia brasileira. Considero que os artigos produzidos por Vieira (1998 e 2003), Froemming et al. (2000), e Sampaio et al. (2012) já foram bem-sucedidos nos seus esforços de análise a respeito da produção brasileira na área de marketing. Dessa forma, não é meu objetivo realizar um inventário da produção da área, uma revisão bibliográfica, ou uma pesquisa bibliométrica.

Dada a liberdade emprestada pela Editoria dessa revista, trago alguns questionamentos pessoais a respeito do conhecimento gerado na área e busco encontrar pontos de tensão. Tais pontos de tensão devem servir para a provocação de debates posteriores, nesse ou em outros fóruns. Portanto, não tenho a pretensão de trazer quaisquer observações ou propostas que possam ser consideradas definitivas. Meu desejo é perturbar um pouco a calmaria que se instalou na área de marketing no Brasil mais recentemente.

Inicialmente, proponho que o leitor me acompanhe em uma rápida trajetória que descreve a configuração da área nos EUA e no Brasil. Meu foco se concentra no desenvolvimento de organizações que têm influenciado a produção de conhecimento na área e, especialmente, as formas com as quais essas influências afetaram a Academia brasileira. Em 
seguida, exponho o leitor ao cenário que se descortina como resultado do caminho trilhado anteriormente.

$\mathrm{O}$ que observo nas publicações da área e procuro chamar a atenção nesse artigo está relacionado i) à cristalização da visada positivista na pesquisa acadêmica em marketing, em claro detrimento de propostas paradigmáticas alternativas; e ii) à preocupação com a aparente acomodação de acadêmicos brasileiros, que aceitam seguir orientações de pesquisa que vêm de fora, quase unicamente dos EUA. Por certo, algumas manifestações contrárias a essa perspectiva de homogeneização do conhecimento da área têm surgido há algum tempo em todo o mundo e podem servir para iniciar um novo debate em nossa Academia.

Dessas tensões levo o leitor a refletir a respeito do engajamento de pesquisadores de marketing em discussões a respeito da relevância do conhecimento produzido e publicado na área; proponho o abandono da metodolatria (CARVALHO DA SILVA, 1988) e a adoção de múltiplas perspectivas paradigmáticas; e sugiro a construção de um espaço para reflexão e desenvolvimento da perspectiva crítica como parte da formação de novos pesquisadores.

\section{Panorama da área de marketing e seus pilares}

Para que seja exposta uma visão um pouco mais profunda a respeito do que é publicado na área de marketing é necessário que se entenda como se configura a Academia de marketing no mundo e a posição relativa da Academia brasileira. A trajetória da Academia de marketing, por sua vez, não está isolada da trajetória da Academia de administração e das escolas de negócios norte-americanas, principalmente. Por mais que $o$ autoproclamado maior encontro mundial de acadêmicos de gestão, o encontro do Academy of Management, não apresente uma divisão específica de marketing, isso não significa que o marketing seja uma área pouco importante para a Academia de gestão norte-americana, para suas escolas de negócios, ou mesmo para as corporações daquele país.

Três organizações ganharam importância na Academia e passaram a tratar mais dedicadamente da orientação a respeito do conhecimento gerado na área de marketing. A primeira delas, a American Marketing Association (AMA) surgiu em 1937 como resultado da fusão entre a National Association of Teachers of Advertisers (NATA) e a American Marketing Society (AMS). Dedicando-se a construir a ponte entre praticantes e acadêmicos de marketing, já em 1938 a AMA foi convidada pelo governo dos Estados Unidos a desenvolver uma definição unificada de marketing para todas as agências governamentais daquele país. Atualmente, a AMA se proclama fonte confiável para praticantes e acadêmicos e continua se preocupando em construir a definição a respeito do que seja marketing. $\mathrm{O}$ seu endereço eletrônico na internet também serve para anunciar quem pretende ser: www.marketingpower.com. Além de magazines, publicações digitais e newsletters, a AMA edita quatro periódicos acadêmicos de elevado impacto: Journal of Marketing; Journal of Marketing Research; Journal of International Marketing; e Journal of Public Policy and Marketing.

O Marketing Science Institute (MSI) foi fundado em 1961 com o objetivo de reduzir a lacuna entre teoria de marketing desenvolvida no ambiente acadêmico e práticas de negócios. Influenciado pela crise de relevância que pairava sobre a Academia de gestão norte americana naquele momento (vide Faria, 
Diga-me o que publicas e te direi quem és: Perspectivas e resistências na publicação da produção de conhecimento em Marketing

2007), desde sua criação o MSI tem dirigido esforços para a construção de uma ciência do marketing. Conforme suas origens o definem, o MSI tem se dedicado a desenvolver uma agenda de geração de conhecimento em marketing baseada no rigor metodológico e ampla utilização de métodos quantitativos. Dessa forma, considera que o conhecimento de marketing será reconhecido como válido e legítimo tanto por praticantes, quanto por cientistas de outras áreas. Diferentemente da AMA, que foi formada por associações de educadores e praticantes de marketing, o MSI é uma organização formada a partir da associação de corporações e não aceita membros individuais. $\mathrm{O}$ seu conselho curador, formado por representantes das corporações associadas ao MSI e representantes da comunidade acadêmica, identifica o que considera como os temas de importância central para os negócios e lança a cada dois anos seu documento de prioridades de pesquisa. A partir desse documento, o MSI estrutura programas de pesquisa que incluem financiamentos a pesquisadores de todo o mundo.

Considero ainda que uma terceira organização tem influenciado fortemente os acadêmicos da área de marketing, mesmo não sendo propriamente uma associação focada em problemas de marketing, mas na pesquisa do consumidor. A Association for Consumer Research (ACR) surgiu a partir da reunião de um grupo de pesquisadores interessados em estudar o consumidor no final dos anos 1960 e organizou a primeira de suas concorridas conferências em 1970. A ACR tem uma proposta um pouco distinta das outras duas organizações citadas. Sua missão declarada é promover o desenvolvimento da pesquisa sobre o consumidor e facilitar o intercâmbio da produção de conhecimento entre acadêmicos, indústria e governos em todo o mundo. Sua logomarca traz uma representação desses três grupos de interesse e a associação tem dado suporte contínuo ao movimento intitulado Transformative Consumer Research (TCR), que está focado no desenvolvimento de pesquisas que tratem do bem-estar e da qualidade de vida do consumidor. Com a expansão da pesquisa sobre consumidor, a ACR conquistou mais prestígio no meio acadêmico. Ainda assim, não é visível uma orientação paradigmática específica nos trabalhos produzidos $\mathrm{e}$ publicados em seus anais (Advances in Consumer Research). Mesmo que possa ser considerada certa predominância de abordagens centradas no positivismo (mais especificamente na psicologia cognitiva), outras perspectivas epistêmicas e estratégias metodológicas convivem em relativo equilíbrio no seio da ACR. Os seus críticos, contudo, rejeitam o alinhamento da ACR à ideologia neoliberal, baseada em uma pseudo-individualidade garantida através do consumo de produtos produzidos em massa. A alienação da dependência de produtos inseridos na ordem capitalista moderna é geralmente deixada de lado mesmo em trabalhos que adotam perspectivas interpretativas (FIRAT e TADAJEWSKI, 2011).

No passado recente, não foram poucos os acadêmicos brasileiros que se aproximaram dessas organizações e atuaram como disseminadores (conscientes ou não) de suas intenções. Movidos pela necessidade de inserção internacional de seus programas, pesquisadores partiram para o estabelecimento de contatos entre a Academia brasileira e a norte-americana. Em diversos debates a respeito do conhecimento que deveríamos desenvolver na Academia brasileira de marketing foram listados os milestones da AMA, ou discutidas as prioridades de pesquisa do MSI. A ACR chegou a promover em 2008 uma conferência latino-americana em São Paulo que contou com participação de importantes pesquisadores estrangeiros e teve presença maciça de acadêmicos brasileiros ${ }^{\text {ii }}$. 
Não obstante, alguns pesquisadores manifestaram intenso desconforto em seguir essas premissas definidas em realidades distintas da brasileira e guiadas por interesses que não estavam baseados nos interesses da sociedade local. Por vezes, foram rotulados como ingênuos ou como encrenqueiros. Em qualquer um dos casos, deveriam ficar de fora da área e ser lançados ao esquecimento, pois não contribuíam para a construção da área (e de uma ciência). Essa forma de agir coincide com o que Willmott (2011) classificou como um processo de discriminação sistemática de pesquisas emergentes, geralmente críticas, que leva pesquisadores a tratarem de tópicos triviais com base em metodologias conservadoras. Com isso, as áreas de Estratégia, Empreendedorismo e Estudos Organizacionais ganharam pesquisadores competentes, que mesmo não tendo sido sempre recebidos de braços abertos, passaram a oferecer relevância a essas outras áreas.

Para aqueles que se sentiam à vontade com as orientações da AMA, do MSI, ou da ACR não parecia estranho conseguir publicar seus artigos em periódicos internacionais, uma vez que guiavam-se pelas orientações dessas organizações. Entretanto, poucos efetivamente atingiram esse resultado. Dois motivos parecem ser os mais comuns para o insucesso: i) deficiências na expressão escrita da língua inglesa; e ii) desinteresse de editores de revistas estrangeiras por problemas ou abordagens locais.

No tocante à dificuldade com a língua inglesa, duas formas para superação desse problema passaram a ser utilizadas: a contratação de (caros) revisores especializados, ou a associação a acadêmicos estrangeiros nativos na língua inglesa com interesses próximos àqueles dos autores nacionais. A contratação de revisores especializados, geralmente indicados pelo editor do periódico ao qual foi submetido o trabalho, acaba por servir como um movimento de enquadramento a jato. Em alguns dias o pesquisador recebe uma lista de pontos a serem tratados e incongruências a serem resolvidas que incluem referências bibliográficas que devem ser incluídas (invariavelmente de artigos previamente publicados no periódico em que se deseja publicar) e, frequentemente, orientações acerca de abordagens teóricas que $o$ autor deve seguir se desejar realmente que o artigo seja aprovado. Tal suporte configura-se praticamente como uma coautoria. Em alguns casos, ao seguir as orientações e tornar-se bem-sucedido em seu propósito de publicar em periódico internacional, o pesquisador comemora, mas já não reconhece tão claramente seus traços em seu próprio trabalho.

As associações entre pesquisadores brasileiros e estrangeiros com interesses similares é uma consequência desejável e, de certa forma, natural. Ao participarmos de reuniões científicas no exterior e nos expormos à comunidade acadêmica internacional, passamos a contribuir para a construção da área. $\mathrm{O}$ encontro de afinidades acadêmicas pode ser mutuamente influenciador e engrandecedor e dar impulso a novas pesquisas, geralmente consolidadas em estágios pós-doutorais. No entanto, nem sempre essas aproximações são realmente exitosas. Por vezes, é necessária a revisão do objeto de pesquisa, o que atende, via de regra, aos interesses do pesquisador estrangeiro. Quando isso ocorre, os desgastes são inevitáveis e novas contribuições tornamse inviáveis.

Parcerias à distância, que não estão baseadas em estágios pós-doutorais, podem ainda sofrer outros tipos de percalços. Acadêmicos estrangeiros não costumam ser muito tolerantes com respeito a interrupções e atrasos nos calendário de 
Diga-me o que publicas e te direi quem és: Perspectivas e resistências na publicação da produção de conhecimento em Marketing

reuniões e tarefas que envolvem o desenvolvimento de pesquisas conjuntas. Tal calendário parece ser incompatível com a rotina de professores brasileiros composta por, no mínimo, duas turmas de graduação e mais uma de pós-graduação

\section{Panorama local da área de marketing}

Não temos no Brasil uma associação de pesquisadores de marketing e, por conta disso, cabe à Associação Nacional de Pós-Graduação e Pesquisa em Administração (ANPAD) abrir espaço para a divisão de marketing em seus eventos anuais e em um evento temático bienal. A ANPAD é constituída por programas de pós-graduação e certamente tem que atender aos interesses desses programas, não necessariamente dos pesquisadores. Ainda assim, o espaço oferecido pela ANPAD à área de marketing já foi palco de debates estimulantes e intensos entre acadêmicos. Contudo, há algum tempo a comunidade de pesquisadores tem se acomodado e poucas discussões têm sido levantadas. Os painéis da divisão têm se dedicado prioritariamente a apresentações e esclarecimentos a respeito de métodos quantitativos considerados inovadores $\mathrm{e}$ estratégias para publicação no exterior, sem muita discussão substantiva. Parece que a motivação para participação da comunidade de pesquisadores da área está concentrada na ideia de conseguir emplacar um artigo em periódico estrangeiro com fator de impacto elevado.

Mesmo acreditando que haja verdadeiro interesse do atual diretor científico da ANPAD em estimular a reconstrução de um espaço para debates mais vibrante, a participação de pesquisadores na construção da área na ANPAD ${ }^{\text {iii }}$ tem sido tímida e/ou reduzida às ações de disseminação das orientações vindas de fora.

Tal comportamento dos pesquisadores da área ajuda a manter verdadeiras as afirmações de Vieira (2003) e Faria stricto sensu, previstas no contrato da maioria dos acadêmicos, que ainda completam sua renda (e seu tempo) com, pelo menos, mais uma turma de pósgraduação lato sensu.

(2004): na falta de orientação própria a respeito do que devemos perseguir, seguimos o que é determinado pela Academia dos EUA. Trocando em miúdos, seguimos os preceitos definidos por AMA (leia-se: praticantes e escolas de negócios dos EUA), MSI (leia-se: interesses diretos das grandes corporações transnacionais), ou ACR (leia-se: ideologia neoliberal). Tal fato ganha contornos ainda mais desagradáveis quando percebemos que a pesquisa no Brasil é basicamente financiada pelo Estado. Inadequado, se não fosse, no mínimo, estranho.

Em recente artigo, Sampaio et al. (2012) trazem algumas conclusões que confirmam grande parte das observações anteriormente realizadas por Vieira (1998 e 2003) e Froemming et al. (2000): i) a abordagem positivista é predominante na área de marketing; ii) há excessiva replicação da produção norte-americana; iii) há uma clara preferência por parte de editores de periódicos a artigos empíricos que apresentem rigor metodológico e orientação positivista; e iv) temas substantivos não são considerados importantes pela área, que enfoca em especialização e sofisticação metodológica.

$\mathrm{O}$ que temos hoje na Academia de marketing é uma cristalização da ênfase no rigor metodológico e a defesa permanente de uma abordagem monoparadigmática, baseada no positivismo. Essa posição é muitas vezes justificada pela tentativa de se construir uma "ciência do marketing", mas deixa clara, na verdade, a incapacidade ou o desinteresse dos acadêmicos em se envolverem com a construção de um conhecimento original para a disciplina. 
A predominância da abordagem positivista também ocorreu em outras ciências humanas e sociais, ditas "soft", conforme salienta Carvalho da Silva (1988). Para serem considerados científicos os estudos desenvolvidos por esses cientistas precisavam atender aos requisitos sistemáticos de relevância explicativa e de contraste empírico, fossem estes de caráter dedutivista ou gerados através de explicações probabilísticas (CARVALHO DA SILVA, 1988, p. 3). Essa abordagem pressupõe a existência de um "método científico", no singular, o que denota a presunção de que haja apenas uma forma correta de se fazer pesquisa. Essa superestimação do método acaba gerando distorções, tais como programas de pósgraduação que dividem suas linhas de pesquisa em quantitativa e qualitativa, ou mesmo acadêmicos que afirmam que experimentos são os seus objetos de pesquisa.

Há que se considerar o quanto o posicionamento monoparadigmático é útil para a manutenção do status quo. $\mathrm{O}$ debate epistêmico também é um debate político que envolve principalmente o questionamento a respeito da dominância em uma área de conhecimento por parte de um grupo que define as formas de acesso a essa área. Pôr em dúvida paradigmas coloca em xeque posições, rankings, condições e, em última análise, traz instabilidade ao modo de operação. Multiplicidade paradigmática significaria compartilhamento de poder e é fácil compreendermos recrudescimento de posições como forma de resistência a movimentos de mudança.

Alguns efeitos danosos para a área já estão sendo sentidos na formação de novos pesquisadores. Os departamentos de marketing começam a liderar propostas de limitação do acesso aos programas de pósgraduação àqueles que apresentem proficiência em métodos quantitativos, aceitem a proposição monoparadigmática e sigam exclusivamente orientações positivistas. A unicidade paradigmática, associada às facilidades atuais de coleta e tratamento de dados quantitativos, também é consistente com a exacerbação do produtivismo (vide SAMPAIO et al., 2012; GODOI e XAVIER, 2012).

Como já apontado por Alcadipani (2011), os alunos de pós-graduação são levados a encarar a produção acadêmica como um fim em si mesmo e passam a integrar a engrenagem de produção que lhes é imposta. Tal procedimento gera mais pontos para o programa e deixa os orientadores satisfeitos, mas resulta, na maioria dos casos, em pesquisas superficiais e falhas na formação de novos acadêmicos.

Para dar suporte à proposta de formação de recursos humanos em grandes quantidades (mais produtivismo!), os formatos de programas de pós-graduação são alterados e passam a ter duração reduzida. Obviamente, isso implica em mudanças no produto final da formação do mestre ou doutor. Dissertações e teses transformam-se em artigos estendidos ou mesmo na soma de artigos publicados. A justificativa é sempre baseada no conveniente e seguro "lá fora já é assim". Para facilitar o processo de adequação/dominação as aulas serão dadas em inglês (por professores brasileiros, para alunos brasileiros...) e seguirão as ementas de disciplinas das melhores escolas de negócios norte-americanas. Não será necessário, ou mesmo possível, sugerir a leitura de algo que seja produzido fora do império. $\mathrm{O}$ conhecimento que for gerado no país deverá ser validado por publicações de alto impacto estrangeiras ou então será considerado de baixa qualidade, não relevante e pronto para o esquecimento. $\mathrm{O}$ patrimônio intelectual das 
Diga-me o que publicas e te direi quem és: Perspectivas e resistências na publicação da produção de conhecimento em Marketing

instituições de pesquisa passará a ser construído a partir de agora.

Novos doutores são formados sem terem tido tempo para reflexão, crítica ou convivência com outras visões paradigmaticas. Permanecem infantilizados (GODOI e XAVIER, 2012) e quando forem chamados a liderarem a formação de recursos humanos e orientarem pesquisas repetirão o mesmo processo de forma natural. Da mesma forma, agirão de maneira enviesada quando estiverem na posição de avaliadores de trabalhos de seus pares ou quando forem alçados à posição de editores. Todo o processo de geração de conhecimento está comprometido a partir da base de sua estrutura. Estamos nos eximindo da responsabilidade de discutir a área e também a formação de novos pesquisadores. Como consequência, fica estabelecido que novos doutores e mestres devam dedicar-se a seguir o que é considerado relevante por editorias de revistas internacionais de alto impacto. Essas revistas encontram-se eminentemente a cargo de acadêmicos norteamericanos, conforme mostrado por Murphy e Zhu (2012), e o ciclo se fecha.

A domesticação do corpo docente de programas de pós-graduação se dá a partir de sistemas de avaliações permanentes: de alunos, de pares, de consultores externos. A instabilidade e a precarização do emprego atingirá todos os acadêmicos (ALCADIPANI, 2011). Mesmo aqueles abrigados em programas de instituições públicas terão suas participações como professores ou orientadores de novos doutorandos dependentes de processos de credenciamento baseados em pontos por publicação. A senioridade será ignorada e os resultados obtidos no último triênio e o potencial de pontuação futura guiarão a percepção a respeito de qualquer acadêmico. Não é preciso dizer que aqueles que se dedicarem à visão crítica ou a temas considerados exóticos (raça, gênero, pobreza, por exemplo) serão considerados inadequados, quando não ridicularizados.

Acadêmicos de marketing de fora dos EUA (mas, notadamente, da Europa) já têm manifestado suas posições contrárias ao processo de homogeneização do conhecimento da área (BROWNLIE et al., 1999; SAREN et al., 2007; FIRAT e TADAJEWSKI, 2007; e no Brasil, FARIA, 2004), mais ainda há dificuldade na consolidação de novas propostas para o desenvolvimento de conhecimento em marketing. Outras áreas de pesquisa locais, como a de Estudos Organizacionais já avançaram de forma mais consistente na proposição de diferentes formas de geração de conhecimento e publicações.

\section{Considerações finais}

O que observo nas publicações da área e procuro chamar a atenção nesse ensaio está relacionado i) à cristalização da visada positivista na pesquisa acadêmica em marketing, em claro detrimento de propostas alternativas; e ii) à preocupante acomodação de acadêmicos brasileiros, que aceitam seguir orientações de pesquisa que vêm de fora, em busca de pontos e não de relevância.

Como consequência da preocupação extrema com o rigor metodológico, que só atende às preocupações de acadêmicos, e do distanciamento dos interesses dos praticantes e da sociedade, a área de marketing vive uma crise de relevância (conforme apontado por Faria em 2004). Ainda assim, os acadêmicos da área parecem não perceber que o rei está nu e continuam seguindo as orientações externas sem oferecer resistência.

Os problemas relacionados às relações entre mercados, consumidores, governos, empresas e sociedade permanecem vivos em volta das pessoas. Essa realidade é muito complexa e não parece ser objeto de atenção ou reflexão por parte dos acadêmicos da área de marketing. Outras áreas, tais como a sociologia, a 
demografia, a geografia ou a antropologia têm se dedicado a tratar desses problemas com abordagens mais interessantes e próximas a responder às dúvidas da sociedade. Por consequência, tornam-se mais relevantes para tratar de problemas de mercado do que a área de marketing. Rossi et al. (2012) apontam que a incidência de utilização de artigos produzidos na área de marketing por outras áreas é baixa e concentrada em aspectos metodológicos. Pouca contribuição substantiva é desenvolvida pela área.

É importante para a própria sobrevivência da área que o conhecimento gerado e publicado por pesquisadores de marketing seja relevante. A produção de conhecimento em marketing tem que abandonar seu isolamento e encarar a realidade multifacetada que cerca a área. Observo que esse movimento já acontece em algumas frentes, principalmente na Europa $^{\text {iv }}$, mas considero que também temos que assumir um papel mais propositivo na Academia brasileira. Para tanto, sugiro algumas possibilidades de ação.

Em primeiro lugar, é necessário chamar a atenção da comunidade acadêmica e retomar espaços para o debate na área de marketing. A discussão entre pares deve ser capaz de apontar outras possibilidades de pesquisa e de geração de conhecimento para área. Uma vez aberto o espaço, devemos colocar em discussão a crise de relevância da área, o afastamento entre o conhecimento gerado e publicado em marketing e os interesses da sociedade local, além da falta de importância da área frente às demais ciências.

Em paralelo, é necessário que ortodoxias metodológicas sejam desmontadas e que o conhecimento da área seja reconhecido como multiparadigmático. Métodos são escravos dos problemas de pesquisa, não o contrário ${ }^{\mathrm{v}}$. $\mathrm{O}$ reconhecimento da multiplicidade e da pluralidade da área é crucial para que haja relevância (MÖLLER et al. 2011). Não se trata de abolir o uso de perspectivas positivistas, afinal, vários problemas de marketing podem ser evidentemente resolvidos a partir de formulações positivistas (SAUERBRONN; CERCHIARO; AYROSA, 2011). Existem, contudo, problemas que não podem ser acessados por esse tipo de visada, pois a forma com a qual $\mathrm{o}$ pesquisador enxerga $\mathrm{o}$ mundo determina que problemas ele pode perceber. A área deve aceitar que a discussão a respeito de método deva ser secundária frente à procura por contribuições substantivas.

Por fim, é fundamental repensar a formação do pesquisador da área. A participação de pesquisadores em formação nas discussões a respeito da orientação da área é desejável, afinal a recuperação da área depende deles. A exposição a múltiplas propostas pode ajudar a formar pesquisadores mais completos e mais capazes de trazer contribuições efetivas para área. Além de participar dos debates, os pesquisadores (formados e em formação) têm que ter espaço para reflexão. Esse tempo para refletir deverá incluir a análise crítica do que eles mesmos vêm desenvolvendo como pesquisa (primeiras indicações já foram desenvolvidas por Vieira et al., 2002; e Maranhão et al., 2008). Isso significa que produziremos muito menos, mas deveremos ser capazes de atrair atenção de outros pesquisadores, da área e de outras áreas, para o que produzimos, não para o quanto produzimos. Deixaremos o caminho do produtivismo em direção à construção da relevância da área de marketing. 
Diga-me o que publicas e te direi quem és: Perspectivas e resistências na publicação da produção de conhecimento em Marketing

\section{Referências}

ALCADIPANI, R. A Academia e a fábrica de sardinhas. Organizações \& Sociedade, v.18, n.57, p. 345-348, 2011.

ARNDT, J. On making marketing science: role of orientations, paradigms, metaphors and puzzle solving. Journal of Marketing, v.49, n.2, p.11-23, 1985.

BROWNLIE, D.; SAREN, M. WENSLEY, R.; WHITTINGTON, R. Rethinking Marketing - towards critical marketing accountings. London: Sage, 1999.

CARVALHO DA SILVA, R. A falsa dicotomia qualitativo-quantitativo: paradigmas que informam nossas práticas de pesquisa. In: ROMANELLI, G.; BIASOLI-ALVES, Z. M. M. (Eds.), Diálogos metodológicos sobre práticas de pesquisa. Ribeirão Preto: Legis Summa, 1998.

FARIA, A. Em busca de relevância no âmbito de estratégia de Marketing. In: XXVIII Encontro Nacional dos Programas de Pós-Graduação em Administração ENANPAD. (2004: Curitiba). Anais... Marketing. Rio de Janeiro: Associação Nacional de Programas de Pós-Graduação em Administração, 2004. (Texto Integral em CD-ROM dos Anais do $28^{\circ}$ ENANPAD).

FARIA, A. Rigor ou relevância? GV Executivo, v.6, p.39-43, 2007.

FIRAT, A. F.; TADAJEWSKI, M. Critical marketing - marketing in critical condition. In: MACLARAN, P.; SAREN, M.; STERN, B.; TADAJEWSKI, M. The SAGE Handbook of Marketing Theory. London: Sage, 2011.

FROEMMING, L. M. S.; LUCE, F. B.; PERIN, M. G.; SAMPAIO, C. H.; BEBER, S. J. N.; TREZ, G. Inventário de artigos científicos na área de marketing no Brasil. Revista de Administração
Contemporânea, v.4, n.2, p.159-173, 2000.

GODOI, C. K.; XAVIER, W. G. O produtivismo e suas anomalias. Cadernos EBAPE.BR, v. 10, n.2, p. 456-465, 2012.

MARANHÃO, C. M. S. A.; MOTTA, F. M. V.; LEITÃO, P. C. C. Por uma educação crítica em marketing: o modelo das três dicotomias de Hunt como ferramenta introdutória? Ensaios Científicos, v.3, p.191-212, 2008.

MÖLLER, K.; PELS, J. SAREN, M. The marketing theory or theories into marketing? Plurality of research traditions and paradigms. In: MACLARAN, P.; SAREN, M.; STERN, B.; TADAJEWSKI, M. The SAGE Handbook of Marketing Theory. London: Sage, 2011.

MURPHY, J.; ZHU, J. Neo-colonialism in the academy? Anglo-American domination in management journals. Organization, v.19, n.6, p.915-927, 2012.

ROSSI, C. A. V.; SILVEIRA, C. S.; ESTEVES, P. S. O Que os Outros Pensam sobre Marketing? A Contribuição da Disciplina para as Ciências Sociais In: Encontro de Marketing da ANPAD 2012. (2012: Curitiba). Anais... Rio de Janeiro: Associação Nacional de Programas de PósGraduação em Administração, 2012. (Texto Integral em CD-ROM dos Anais do EMA 2012).

SAMPAIO, C. H.; PERIN, M. G.; LUCE, F. B.; SANTOS, M. J.; SANTINI, F. O.; OLIVEIRA, M. O. R.; LENZ, G. S. Pesquisa científica da área marketing no Brasil: uma revisão da primeira década do século XXI. Revista de Administração Contemporânea, v.16, n.3, p.459-478, 2012.

SAREN, M.; MACLARAN, P.; GOULDING, C.; ELLIOTT, R.; SAHNKAR, A.; CATTERALL, M. (Eds.) Critical Marketing: defining the field. Oxford: Butterworth-Heinemann, 2007. 
SAUERBRONN, J. F. R.; CERCHIARO, I. B.; AYROSA, E. A. T. Uma discussão acerca de métodos alternativos em pesquisa acadêmica em marketing. Gestão \& Sociedade, v.5, n.12, p.254-269, 2011.

VIEIRA, F. G. D. Por quem os sinos dobram? Uma análise da publicação científica na área de marketing do Enanpad In: XXIII Encontro Nacional dos Programas de Pós-Graduação em Administração - ENANPAD. (1998: Foz do Iguaçú). Anais... Marketing. Rio de Janeiro: Associação Nacional de Programas de Pós-Graduaço em Administração, 1998. (Texto Integral em CD-ROM dos Anais do $22^{\circ}$ ENANPAD).

WILLMOTT, H. Journal list fetishism and the perversion of scholarship. Organization, v.18, n.4, p.429-442, 2011.

\footnotetext{
' Uma vista ao site www.msi.org pode ser mais esclarecedora. Logo na página de abertura está disponível o link para o documento de prioridades de pesquisa para o biênio 2012/2014 ("What are Marketers' top concerns?" anuncia o link). Ao final do documento é possível conhecer a lista de empresas associadas.

ii Diante do hiato de mais de quatro anos e do crescente interesse da comunidade acadêmica brasileira por pesquisas de consumo (as áreas Comportamento do Consumidor e Cultura e Consumo, abarcadas pela temática da ACR, foram responsáveis por mais de $40 \%$ das submissões no último encontro de Marketing da ANPAD), não seria surpreendente que o Brasil voltasse a sediar uma edição desse encontro no futuro próximo.

iii A ausência de chapas concorrentes nas últimas eleições para chefe de divisão de marketing da ANPAD pode indicar a desmotivação para o debate.

${ }^{\text {iv }}$ Em especial o esforço de criação de uma divisão de Marketing Crítico dentro das conferências do Critical Management Studies (CMS) e a iniciativa do Interpretive Consumer Research dentro do European Institute for Advanced Studies in Management (EIASM).

${ }^{v}$ Assim argumentava frente a seus alunos o saudoso Marcelo Milano.
}

VIEIRA, F. G. D. Narciso sem espelho: a publicação brasileira de marketing. Revista de Administração de Empresas, v.43, n.1, p.81-90, 2003.

VIEIRA, R. S. G.; DIAS, C. M.; RODRIGUES FILHO, J.; ANJOS NETO, M. O Conhecimento do Marketing Sob os Olhos da Teoria Crítica. In: XXVI ENCONTRO NACIONAL DOS PROGRAMAS DE PÓS-GRADUAÇÃO EM ADMINISTRAÇÃO - ENANPAD. (2002: Salvador). Anais ... Marketing. Rio de Janeiro: Associação Nacional de Programas de Pós-Graduação em Administração, 2002. (Texto Integral em CD-ROM dos Anais do $26^{\circ}$ ENANPAD). 